\title{
Local Nodes in Global Networks: The Geography of Knowledge Flows in Biotechnology Innovation
}

\author{
M. S. GERTLER* \& Y. M. LEVITTE** \\ *Munk Centre for International Studies, University of Toronto, Toronto, Canada, \\ ${ }^{*}$ Department of City and Regional Planning, Cornell University, Ithaca, NY, USA
}

\begin{abstract}
Aвstract The literature on innovation and interactive learning has tended to emphasize the importance of local networks, inter-firm collaboration and knowledge flows as the principal source of technological dynamism. More recently, however, this view has come to be challenged by other perspectives that argue for the importance of non-local knowledge flows. According to this alternative approach, truly dynamic economic regions are characterized both by dense local social interaction and knowledge circulation, as well as strong inter-regional and international connections to outside knowledge sources and partners. This paper offers an empirical examination of these issues by examining the geography of knowledge flows associated with innovation in biotechnology. We begin by reviewing the growing literature on the nature and geography of innovation in biotechnology research and the commercialization process. Then, focusing on the Canadian biotech industry, we examine the determinants of innovation (measured through patenting activity), paying particular attention to internal resources and capabilities of the firm, as well as local and global flows of knowledge and capital. Our study is based on the analysis of Statistics Canada's 1999 Survey of Biotechnology Use and Development, which covers 358 core biotechnology firms. Our findings highlight the importance of inhouse technological capability and absorptive capacity as determinants of successful innovation in biotechnology firms. Furthermore, our results document the precise ways in which knowledge circulates, in both embodied and disembodied forms, both locally and globally. We also highlight the role of formal intellectual property transactions (domestic and international) in promoting knowledge flows. Although we document the importance of global networks in our findings, our results also reveal the value of local networks and specific forms of embedding. Local relational linkages are especially important when raising capital-and the expertise that comes with
\end{abstract}


it-to support innovation. Nevertheless, our empirical results raise some troubling questions about the alleged pre-eminence of the local in fostering innovation.

KEY WORDS: Knowledge flows, biotechnology, buzz, inter-firm collaboration

\section{Introduction: The Geography of Innovation in the Learning Economy}

With the advent of the learning economy, it is widely agreed that competition between firms is increasingly based on the production, appropriation and distribution of knowledge. While this is true of all industries to some extent-even older, more traditional economic activities can benefit from the adoption of more innovative products and production processes - it is especially so for the most knowledge-intensive economic activities.

Biotechnology, as a highly science-based sector, is one of the most knowledge-intensive forms of activity in the contemporary economy. Its emergence is expected to have a major impact on regional and national economies, both directly and indirectly. The production of biotechnology products represents a relatively new and significant growth phenomenon on its own. Over the long run, the growth potential associated with the wider diffusion and use of biotechnology products and processes, and their convergence with information technologies, nanotechnologies and other applied sciences, is probably even greater. In this sense, biotechnology appears to have the characteristics of a core technology, with the potential to underpin a new technoeconomic paradigm.

It is therefore not surprising that the innovation process within biotechnology firms has become a subject of major interest to social scientists. Despite this recent interest, however, we are still far from a consensus on the nature of the innovation process in this industry, and it is the geography of this process that seems to be at issue. On the one hand, some see this process as a global battle between several major players. In this view, the very high degree of knowledge intensity in this industry means that there is a strong "science push" along the trajectories of a linear model of innovation from the university laboratory to the marketplace. Large up-front costs associated with multi-year research and development $(R \& D)$ processes, followed by expensive regulatory reviews and trials, raise barriers to entry. Hence, large firms operating on a global scale are the dominant players. While there may be certain acknowledged geographical centres of research excellence, their locational pull is diminished by the efficient international circulation of scientific knowledge in codified form, in the form of journals, conferences, patents, technology licences and other well-established practices of research dissemination. ${ }^{1}$

At the same time, there is evidence of a paradoxical development in the knowledge economy: knowledge-intensive economic activities-the most 
potentially footloose of all activities-exhibit high levels of geographical concentration. Indeed, the most knowledge-intensive of these activities seems to show the highest degree of geographical concentration. In the case of biotechnology, this pattern of spatial concentration appears to be strong and, if anything, becoming stronger rather than weaker over time (Feldman, 2001).

This locational tendency towards geographical clustering appears to be consistent with a large literature in economic geography and industrial economics attesting to the role of agglomeration, clustering and localized learning in fostering innovation and dynamic economic growth (Maskell and Malmberg, 1999; Storper and Venables, 2002). The key idea here is that, if innovation as an activity has become increasingly interactive and socially organized (in contrast to more traditional conceptions based on a linear model), then geographical concentration of the relevant actors will facilitate this process of learning-by-interacting. Such dynamics may help to explain why, for example, there appear to be strong spatio-temporal spillover effects in the knowledge production process in biotechnology and related sciences (Feldman, 2000), despite the ready codifiability and accessibility of research findings on a global basis.

While arguments concerning the importance of localized learning dynamics have acquired the status of "received wisdom" in recent years, some economic geographers have also expressed considerable unease with the idea that learning processes are exclusively local (Amin, 2000; Allen, 2001). While many still acknowledge the critical role of localized learning in the innovation process, there is a growing recognition that locally based learning is likely to be most effective when the actors involved remain fully open to new knowledge flows from around the world. From an evolutionary perspective, such inflows serve to increase the diversity of ideas within the local knowledge base, leading to potentially richer innovation dynamics (Malmberg and Maskell, 2002). In a recent paper, Bathelt et al. (2004) argue that these non-local connections are far from randomly distributed across the globe, but can be thought of as global "pipelines" extending between centres of localized learning, and buttressed by corporate links effected by the large global players in sectors such as biotechnology. Such pipelines, in their view, are essential complements to the "local buzz" that is produced and reproduced in agglomerated centres where innovative activity is concentrated. Both

\footnotetext{
${ }^{1}$ In a recent overview of the "geography of innovation" literature, Asheim and Gertler (2005: 296-298) note that biotechnology draws primarily upon "analytical" forms of knowledge that, at least in theory, are relatively easily codified and transmitted across long geographical distances and cultural/institutional divides. However, they also note the marked tendency for biotech innovation to cluster geographically, and offer further insights as to why this might be the case, emphasizing the continuing importance of local networks and relations, as well as the growing importance of quality of place in attracting and retaining the highly educated people that typically work in this sector.
} 
geographies are essential to ensure the innovative dynamism of participating firms over time.

The purpose of this paper is to advance our understanding of the innovation process within the biotechnology industry, one of the most knowledge-intensive of all industries in today's economy. The goal is to develop a better sense of the interplay or balance between global and local forces and flows, thereby enabling us to examine the very interesting conceptual arguments concerning local buzz and global pipelines through the lens provided by a unique empirical example: a recent national survey of biotechnology firms in Canada. In the following section we review the recent literature on the nature and geography of innovation and commercialization in biotechnology, enumerating some unresolved questions and hypotheses that emerge from this literature. Following this, we discuss the unique source of data used for the empirical analysis, the 1999 Canadian Biotechnology Use and Development Survey, and present our findings. We conclude this paper with a discussion of the conceptual and policy implications arising from this analysis.

\section{The Spatial Structure of Knowledge Production and Circulation in Biotechnology}

Competence-based views of the firm (Penrose, 1959; Kay, 1993; Cohendet et al., 1999) argue that the innovative performance of the firm depends on the resources and capabilities it acquires or develops, in the form of investments in R\&D, skilled human capital, and organizational routines, relationships and other practices. Some of the firm's capabilities may also be developed through interaction with other firms or institutions external to the firm itself, through a process that has come to be known as learning by interacting (Lundvall and Johnson, 1994). Restating this in a slightly different way, the "resources" that are critical to the firm's success may be inside or outside the firm. If the latter, then the next question is: where are these crucial "relational resources" most likely to be found?

Previous research on innovation in biotechnology firms suggests that access to knowledge and capital are essential determinants of firms' research capabilities and their success in commercializing the outputs of such research. Classic studies of the emergence of the US biotech industry support the view that knowledge spillovers from universities are key to firm start-ups (Zucker and Darby, 1996; Zucker et al., 1998a, b; Feldman, 2001; Prevezer, 2001). Empirical evidence suggests that these knowledge flows are highly localized. For example, Zucker et al. (1998a) find that the number of products in development by firms is positively and significantly related to the number of university stars ${ }^{2}$ in their geographical area. They argue that star scientists do not freely give away their intellectual property but instead enter into contractual arrangements with existing firms or start their own firms to reap the economic returns from their scientific 
discoveries. Their analysis indicates that these scientists work with or create firms within commuting distance of their home or university (Zucker et al., 1998a).

Similarly, Feldman (2001) reports that when scientists in her study were asked where they would locate given unlimited choice, most responded that even though they could locate anywhere in the world (as they were part of global scientific networks) they generally want to "stay put". Using the literature on clusters and regional innovation processes, Feldman (2000: 389) argues that biotech firms are highly concentrated geographically to reduce the distance over which interaction and communication are conducted, and to enhance the coordination of tasks. These aspects of clustering are particularly important for individuals starting a new enterprise who seek to minimize disruption and uncertainty (Feldman, 2001). Moreover, previous research indicates clustering is not only about reducing transaction costs and minimizing risks but also about access to knowledge. Delaney (1993, quoted in Feldman, 2001: 350) finds that "most biotechs use information sources (within a 50-mile radius of the firm)".

The importance of spatial proximity between university-based scientists and companies with the capabilities to commercialize their research is underscored by recent developments within the pharmaceuticals industry-most notably the announcement in May 2002 that Novartis, the Swiss pharmaceuticals group, was moving its research operations to Cambridge, Massachusetts. According to industry analysts, their decision to invest in Cambridge was motivated by the concentration of genomics expertise in the Boston area. This expertise comes in at least three different forms: university and hospital researchers (key producers of potentially commercializable intellectual property), rapidly growing biotech companies such as Biogen, Vertex and Millennium (potential partners in collaborative research), and graduates from world-renowned institutions such as MIT and Harvard (Dyer, 2002b). ${ }^{3}$ Not surprisingly, the US\$250 million Novartis facility, large enough to house 400 scientists, has been constructed within walking distance of MIT's main complex of buildings.

Access to venture capital (VC) is another key factor emerging from prior research on innovativeness and performance in biotechnology, since this key input provides both the investment capital and the entrepreneurial and managerial know-how necessary for commercial success (Zucker et al., 1998b; Niosi, 2000a, b; Cooke, 2001b; Powell et al., 2002). Firms with sufficient access to "patient", "knowledgeable" capital of this sort are more likely to have the managerial and financial resources available to realize their innovation goals, and this is especially relevant for small,

\footnotetext{
${ }^{2}$ Star scientists are defined as outstanding scientists who combine scientific productivity (as measured by number of journal articles while affiliated with the firm) with specific knowledge of the new technique for the commercialization.

${ }^{3}$ Dyer (2002b: 13) quotes Daniel Vasella, chairman of Novartis, as observing that "the biggest pool of untapped scientists and hospital research was in the Boston area".
} 
recently established biotech start-ups with limited internal financial resources. A large body of research suggests that the geographical distribution of VC available for biotech firms is also highly concentrated. Cortright and Mayer (2002) report that since 1996, 75 percent of new VC investment in the USA was located in the five largest biotech clusters (Boston, San Francisco, San Diego, Seattle and Raleigh-Durham). Analyzing the biotech industry directory (BioScan) and Pratt's Guide to Venture Capital, Powell et al. (2002) also find that over 50 percent of biotech firms receive local VC support. Similarly, Niosi notes that in Canada "biotechnology firms tend to cluster in regions where venture capital is abundant" (Niosi, 2000a: 13). In a recent, more detailed analysis, Niosi and Dalpé (2003) demonstrate that Canada's two largest biotech clusters-Toronto and Montreal-show high degrees of local sourcing when it comes to venture financing. On the other hand, smaller Canadian centres exhibit considerably stronger dependencies on external VC sources due to the relatively undeveloped nature of supporting sectors in the local cluster.

The strong clustering of firms around VC sources can be partly explained by the risky nature and lengthy time horizon of investments in bioscience companies: reaping the fruits of such investments may take years. For example, Cooke (2002a) reports that the transformation of scientific research into commercial products can take over 10 years of trials. Moreover, most of these innovations are highly specialized and require investors to be knowledgeable about both the science involved and the competence of the lead researchers. Finally, venture capitalists provide more than just capital: they are also vital sources of managerial expertise to help ensure successful product and business development. Furthermore, Powell et al. (2002: 294) argue that experienced VCs use their abundant contacts to provide referrals to specialized sources of expertise, such as patent lawyers and consultants. Consequently, proximity between researchers and VC fosters trust and the continuing exchange of knowledge.

Even though the biotech industry is clearly one of the most geographically concentrated forms of economic activity, there is a growing appreciation that non-local (national and global) linkages are essential to successful innovation. The evidence to support this argument, however, is somewhat ambiguous. A number of researchers argue that, while biotechnology research is highly concentrated, relationships in the commercialization phase span longer distances (Niosi, 2000b; Prevezer, 2001; Cooke, 2002a; Powell et al., 2002). Maturing biotech firms seek deals with large pharma corporations who will invest in transforming their innovations into products. Cooke (2002a) and Prevezer (2001) argue that some firms also seek customers and VC globally and nationally, as well as regionally.

Local partnerships, on the other hand, are increasingly seen as being especially critical for developing basic research (Niosi, 2000b), and for 
creating a critical mass of research capability (Cooke, 2002a). Powell et al. (2002) find that locally funded firms are smaller, younger and more science-focused (as indicated by the number of PhDs and MDs they employ). These findings, together with data showing that early stage companies are more reliant on local (vs. non-local) VC firms, lead Powell et al. to conclude that local VC support is more important at the early stages of a company's development. Firms that have reached more advanced commercial stages of development are more likely to attract external financing from afar.

The age of a firm is a factor not only among biotech companies but also among the VC firms themselves. Powell et al. find that as these firms grow older and larger they tend to invest more in younger and more distant biotech companies. Although VC is concentrated in Boston, New York and the San Francisco Bay Area, in the last decade New York and Bay Area companies have been increasingly branching out of their own areas to finance firms in each other's backyard and in the Boston area. Boston VC companies, in contrast, have shown a stronger tendency to invest locally.

Cortright and Mayer (2002), in conducting a comprehensive survey of American biotech companies and regions, come to a somewhat different conclusion about the localization of research and VC. They find that research activity (measured through patenting and NIH funding for medical schools) is not very highly concentrated spatially, although "commercialization efforts remained highly concentrated" (p. 33). In contrast to Niosi (2000b), Prevezer (2001), Cooke (2002a) and Powell et al. (2002), Cortright and Mayer's evidence highlights the concentration of VC. They argue that the critical factor in commercializing basic research products is the

very high concentration of capital flows in biotech centers: the nine leading biotech regions account for 88 percent of all venture capital for biopharmaceuticals, 92 percent of the most active biotechnology venture capital firms, and 96 percent of the dollar value of research alliances with pharmaceutical firms. (Cortright and Mayer, 2002: 33-34)

Moreover, four metropolitan areas received over 80 percent of the value of all research contracts.

The above inconsistencies related to the geography of knowledge and capital flows might be resolved by acknowledging that even though biotech firms forge strategic alliances with far-away partners, these non-local alliances are targeted at a few locales, where the specific competence, capital or other required resources are concentrated. For example, Powell et al. (2002) suggest that there are four key centres in which capital circulates (Boston, New York, the San Francisco Bay Area and San Diego). Even though capital flows between these centres and to a minor extent outside them, they still dominate the biotechnology knowledge and capital flows. The geographical focus of the researchers may also explain some of 
the discrepancies in the evidence. Whereas Cortright and Mayer focus on American firms, Niosi (2000b) and Cooke (2002a) extend their evidence to Canada and Europe, respectively. It is possible that the more limited funding capabilities in Europe and Canada require companies there to reach out to large foreign-owned pharma corporations to improve their basic research and commercialization efforts.

In addition, Cortright and Mayer's finding that research is dispersed, in contrast to previous work that finds high degrees of regional concentration, may be a reflection of the maturation of the industry over time. Whereas Zucker and Darby and their collaborators focused on the birth of firms in the late 1980s and early 1990s, Cortright and Mayer examine the current state of a maturing industry.

The above review raises a number of interesting issues for the current study. First, it is clear that there is very little consensus in the literature concerning the relative importance and role of local vs. non-local sources of knowledge and capital in this industry. Second, analyses that focus on the geography of these flows have tended to downplay the internal characteristics and capabilities of the firms themselves. Clearly, a resource- or competence-based view of the firm suggests that our analysis should attempt to capture the influence of internal capabilities as well as those that are generated through interaction with external actors (both local and non-local). Indeed, following Cohen and Levinthal's (1990) influential argument, the presence of well-developed internal capabilities and resources will enhance the absorptive capacity of the firm-that is, its ability to make productive use of new knowledge and ideas from external sources. Third, in a knowledge-intensive industry such as biotechnology, the most important input to the generation of successful new products is undoubtedly highly educated people (embodied knowledge). Therefore, it stands to reason that any analysis of innovation in biotechnology requires a strong focus on human resources and labour market practices.

A recent report documenting the strengths, weaknesses and challenges facing the Canadian biotech industry highlights many of these issues (Ernst and Young, 2002). ${ }^{4}$ By most accounts, Canada is home to the second largest collection of dedicated biotech firms in the world after the USA (Dyer, 2002a). Among Canada's strengths, the report emphasizes good knowledge infrastructure (universities and research centres), worldclass science and technology, well-established tax incentives for R\&D, a favourable exchange rate relative to US and European currencies, a high quality of life that helps attract and retain talented workers, and a geographical concentration of facilities, research and skills in a relatively small number of centres (with Toronto, Montreal and Vancouver leading the way). Among the industry's weaknesses and challenges are thin

\footnotetext{
${ }^{4}$ These highlights are a product of the Canadian Biotechnology Commercialization Roundtable organized by Ernst and Young in March 2002, which brought together industry members and analysts.
} 
domestic capital markets which make it difficult to raise capital and find investment partners, lack of specialization by investment funds, the relatively small size of the Canadian market, a shortage of scientists and managers with experience in biotech start-ups, a relatively weak entrepreneurial culture, and lengthy approval and testing processes. Potential threats facing the industry are its consolidation through acquisitions by foreign firms, a potential "brain drain" to the USA and "uncompetitive" regulatory processes.

\section{Determinants of Innovation in Biotechnology Firms: Data and Variables}

To examine these issues and hypotheses we use a unique database that documents innovation performance and other characteristics of biotechnology firms in Canada: Statistics Canada's 1999 Survey of Biotechnology Use and Development. The survey was conducted in the spring of 2000 and was designed to gather data from two distinct groups of firms: those that use biotechnologies as part of their day-to-day operations, as they would use any other factor of production, and "core" biotech firms-firms that are conducting an active R\&D program in biotechnology and consider biotechnology central to their activities (McNiven, 2001a). The latter group (consisting of 358 core firms) is the focus our analysis, and is believed to be representative of the entire core firm population, based on size, sector and province (see Tables 1-3).

Based on the literature reviewed in the previous section, we hypothesize that the likelihood of innovation is greater for firms that have assembled greater in-house resources and capabilities (which will also enhance their capacity to absorb cutting-edge knowledge from external sources). Therefore, such firms are expected to engage more intensively in $R \& D$, dedicate a higher proportion of their in-house human resources to scientific and technical expertise, and devote greater resources to the recruitment of skilled personnel. We would also expect the probability of innovating will be greater for firms that are well supported by their local milieu, but also link themselves effectively into global networks of knowledge, capital and people. Hence, such firms can be hypothesized

Table 1. Number of core biotech firms by size, Canada, 1999

\begin{tabular}{lc}
\hline & Number of firms \\
\hline Small (50 or less employees) & 270 \\
Medium (51-150 employees) & 51 \\
Large (151 or more employees) & 37 \\
Total & 358 \\
\hline
\end{tabular}

Source: McNiven (2001a). 
Table 2. Number of core biotech firms by sector, Canada, 1999

\begin{tabular}{lc}
\hline & Number of firms \\
\hline Human health & 150 \\
Agriculture & 90 \\
Natural resources & 18 \\
Environment & 35 \\
Aquaculture & 14 \\
Bio-informatics & 18 \\
Food processing & 29 \\
Other & $4^{\mathrm{a}}$ \\
Total & 358 \\
\hline
\end{tabular}

a Use with caution. Unreliable due to high coefficient of variation.

Source: McNiven (2001a).

to have better access to sufficient capital resources (particularly "patient" capital), utilize sources of tacit as well as codified information, and collaborate with local partners but also reach out to external innovation partners and sources of knowledge.

All 358 core biotech firms in the survey can be considered innovative, in the sense that they were (by definition) using at least one of a list of biotechnologies in their operations at the time of the survey. Not all of the firms, however, had successfully produced a new product or process. For the purposes of this analysis, patenting is used as an indicator of tangible output from innovation in biotechnology. Previous analysis of the 1999 Biotechnology Use and Development Survey (McNiven, 2001b) indicates that, of the nearly 8,000 pending and existing patents held world-wide by Canadian biotech firms (3,706 existing, 4,259 pending), 2,300 were held or pending in Europe, followed by the USA $(2,166)$ and Canada $(1,626)$.

Table 3. Number of core biotech firms by province, 1999

\begin{tabular}{lc}
\hline & Number of firms \\
\hline British Columbia & 71 \\
Alberta & 28 \\
Saskatchewan & 16 \\
Manitoba & 6 \\
Ontario & 111 \\
Quebec & 107 \\
Atlantic Canada & 19 \\
Canada $^{a}$ & 358 \\
\hline
\end{tabular}

${ }^{a}$ Includes Nova Scotia, Prince Edward Island, New Brunswick and Newfoundland.

Source: McNiven (2001a). 
Moreover, McNiven reports that although nearly 75 percent of biotech firms are small, they held only 34 percent of patents. Large firms, on the other hand, held over half of the pending and existing patents in 1999 (45 percent of patents in the USA and 60 percent of patents in Europe).

The use of patenting as an indicator of innovation is consistent with a large body of work investigating the nature and geography of innovation in biotechnology and the biosciences more broadly (Zucker et al., 1998a; Feldman, 2000, 2001; Niosi and Bas, 2001; Levin et al., 2001). ${ }^{5}$ Consequently, two dependent variables were formulated to measure innovation. The first is a dichotomous variable [INNOVATION-Y/N]: "yes" if the firm held one or more patents in any geographic region of the world and "no" if the firm had no existing or pending patents. A second variable [INNOVATION INTENSITY] captures the intensity of innovation, measured as the number of existing or pending patents (again, in all geographic regions), divided by the number of biotech employees to remove the possible effects of firm scale on the sheer volume of patenting activity.

Based on the hypotheses outlined above, eight groups of explanatory variables were created: $R \& D$ expenditures per biotech employee [RDSPEND] which measures the R\&D intensity of the firm. In-house scientific capability is measured as the number of biotech employees working in R\&D as a proportion of total biotech employees [INHSTECH]. The hypothesis regarding dedication of greater resources to recruitment of skilled personnel is examined using three variables: the number of different recruiting methods used to fill biotech positions [BIORCRT], problems encountered when searching for new human resources [OBSTHR] and the number of biotech staff hired from outside Canada, as a proportion of total biotech related employment [KNOWFLWGG]. We can also regard this last variable as an indicator of "embodied" international knowledge flow, since the international mobility of highly skilled labour is likely to be a very important channel for the circulation of biotech knowledge.

Since it was hypothesized that innovative firms utilize a broader range of information and knowledge sources than non-innovative ones, we

\footnotetext{
${ }^{5}$ The success of biotechnology firms is often measured by their innovative output rather than by their revenues or profits. Zucker et al. (1998a) point out that revenues are generally non-existent in the young biotech industry and are therefore of limited use as an indicator of firms' success. Innovative outputs, on the other hand, can indicate the ability of a firm to attract VC that in turn allows a firm to develop and commercialize the fruits of its research. Zucker et al. suggest that innovation can be measured by looking at the number of products in development, the number of products on the market and net growth in employment. Nevertheless, they and others agree that patents are perhaps the most useful predictor of commercial values and future returns, and that patents are key to attracting VC to further develop or commercialize innovative products (Niosi, 2000b). Notwithstanding this consensus, it should also be acknowledged that patents as a measure of innovation are subject to some well-known limitations. Many patents are never commercialized. For many forms of innovation, patents may offer only partial protection of intellectual property; for others, patents may be wholly infeasible or impractical (see Teece, 1986; Levin et al., 1987; Klevorick et al., 1995).
} 
created four information and knowledge variables: internal [INTERNAL], codified [CODIFIED], tacit/personal ("embodied") [TACIT] and government [GOVERNMENT]. The Biotech Survey asks firms to rate the importance of various sources of information to their firms on a scale of 1 (low) to 5 (high). If the firm ranked the information source above 3 we computed that source as important. ${ }^{6}$

The hypothesis regarding the relationship between collaboration and innovation was also tested using three variables: the number of collaborative arrangements in which a firm participates [NUMBER OF COLLABORATIVE AGREEMENTS], whether these arrangements were "local" or not, ${ }^{7}$ and whether or not the firm was spun off from another company [SPINOFF]. The survey also collects useful information on flows of intellectual property rights that enables us to track the geography of knowledge inflows and outflows explicitly. To test the importance of domestic vs. international knowledge flows, four variables measuring the presence (yes/no) of inflows and outflows of intellectual property (IP) rights between foreign and Canadian firms were used [IPINF-inflow from foreign firms, IPOUTF-outflow to foreign firms, IPINC_-inflow from Canadian firms, IPOUTC—outflow to Canadian firms].

The last two groups of variables focused on the availability of capital resources, again measured by three different measures-capital raised per biotech employee [CAPITAL RAISED PER EMPLOYEE], the amount of capital raised from "private" or "relational" (and therefore most likely local) sources - that is, the percentage of total capital that was raised from angel investors/family/friends, VC and collaborative alignments [CAPITAL MARKET LINKAGES], and whether or not the firm identified access to capital as a major obstacle to growth [OBSTACLE CAPITAL]. To capture the influence of "life cycle" effects on the likelihood of innovation (patenting), we introduced a set of variables reflecting the stage of development of products and processes. These represent the number of products a firm has in a specific stage of the product development cycle, as a proportion of its total number of products [STAGE-RD, STAGEPRECLINICAL, STAGE-REGULATORY, STAGE-APPROVED]. Our expectation would be that firms that have advanced to later stages of

\footnotetext{
${ }^{6}$ The following are the categories listed in the survey which correspond to each of the variables: Internal-internal sources/staff or parent/subsidiary firm; Codified-academic journals/trade publications, library/literature search, database retrieval services; Tacit/ personal-universities/colleges/private training institutes, personal contact with others, other companies, professional/industry associations, conferences/workshops/trade shows; and Government-federal agencies, provincial agencies.

${ }^{7}$ The survey asks firms for the location of their collaborative partners by country. Therefore, for the purpose of this analysis, "local" partners were defined as those within Canada. Previous work (Ernst \& Young, 2002) confirms that biotech firms are highly concentrated in a few Canadian city-regions, with Toronto, Montreal and Vancouver dominating. This suggests that there is a high likelihood that a partner in the same country is also located within the same city-region.
} 
product/process development would be more likely to have generated patents since, on the whole, they are likely to be older and better able to generate resources internally to support further innovation. Finally, in order to capture the influence of any other resources and capabilities not already explicitly measured, we included a variable to reflect the size of the firm, measured by number of employees [SIZE].

\section{Analysis and Results}

For the dichotomous form of the dependent variable (which measured whether or not a firm has patented) we conducted a logistic regression (see Table 4). The results show that innovating firms dedicate more efforts and resources to HR recruiting, that is, that they use a higher number of different recruiting methods to fill vacant biotech positions. Having employed more recruiting methods, however, innovative biotech companies also report encountering more obstacles in these efforts-perhaps because their human resources needs are more demanding. Contrary to previous research that highlights the importance of tacit sources of information, the use of such sources did not turn out to be a significant predictor of innovativeness. Moreover, even though our analysis shows that innovative biotech firms in Canada are more likely to have spun off from larger firms, biotech innovators are actually less likely to rely on internal sources of information, including the staff from the parent or subsidiary firm. Patenting firms, however, make heavier use of codified sources of knowledge, such as academic journals, trade publications or database and library resources compared to firms that do not patent.

Strikingly, and suggestive of the importance of global pipelines, the data show that knowledge networks of innovative biotech firms are nonlocal-indeed global. Firms that patent are more likely to tap into global knowledge flows of the embodied variety - they hire a significantly larger proportion of their biotech workers from outside of Canada. They are also more likely to grant IP rights to foreign firms, suggesting that commercialization is reliant on relationships with companies outside Canada. Alternatively, one could say that patenting firms are more likely to produce new knowledge that is recognized to have commercial value in the international marketplace. Innovators are also more likely to participate in collaborative agreements. Other variables related to VC did not show a clear direction and were not significant.

Finally, patenting firms are more likely to have a higher proportion of their projects in later (regulatory review) stages of development. This suggests that more mature firms are more likely to have produced tangible outputs from innovation.

Results were similar when innovation was measured by its intensity (number of patents), rather than by the simple presence or absence of patents (see Table 5). Firms that patent more intensively were found to dedicate more effort and resources to human resources recruiting, that is, 
Table 4. Logistic regression analysis: existing/pending patents-yes $/ \mathrm{no}^{\mathrm{a}}$

\begin{tabular}{|c|c|c|c|c|}
\hline Variable & $B$ & Wald & Sig. & $\operatorname{Exp}(B)$ \\
\hline RDSPEND & 0.000 & 1.933 & 0.164 & 1.000 \\
\hline INHSTECH & 0.042 & 0.014 & 0.905 & 1.043 \\
\hline BIORCRT & $0.434^{\star \star \star}$ & 21.465 & 0.000 & 1.543 \\
\hline KNOWFLWGG & $7.005^{\star \star}$ & 5.639 & 0.018 & $1,102.506$ \\
\hline OBSTHR & 0.630 ** & 4.229 & 0.040 & 1.878 \\
\hline INTERNAL & $-1.028^{\star \star}$ & 5.773 & 0.016 & 0.358 \\
\hline CODIFIED & $0.577^{\star \star \star}$ & 6.220 & 0.013 & 1.781 \\
\hline TACIT & -0.254 & 2.695 & 0.101 & 0.776 \\
\hline GOVERNMENT & 0.143 & 0.637 & 0.425 & 1.154 \\
\hline $\begin{array}{l}\text { NUMBER OF COLLABORATIVE } \\
\text { AGREEMENTS }\end{array}$ & $0.112^{*}$ & 3.153 & 0.076 & 1.118 \\
\hline SPINOFF? & $0.573^{\star}$ & 3.238 & 0.072 & 1.774 \\
\hline SIZE & 0.000 & 2.441 & 0.118 & 1.000 \\
\hline CAPITAL RAISED PER EMPLOYEE & 0.000 & 0.230 & 0.631 & 1.000 \\
\hline CAPITAL MARKET LINKAGES & 0.002 & 0.420 & 0.517 & 1.002 \\
\hline OBSTACLE CAPITAL & 0.443 & 1.223 & 0.269 & 1.557 \\
\hline STAGE-RD & 0.196 & 0.240 & 0.624 & 1.217 \\
\hline STAGE-PRECLINICAL & -0.758 & 1.213 & 0.271 & 0.468 \\
\hline STAGE-REGULATORY & $2.564^{\star \star}$ & 4.699 & 0.030 & 12.992 \\
\hline IPINF & -0.616 & 1.811 & 0.178 & 0.540 \\
\hline IPOUTF & $1.277^{\star \star \star}$ & 7.219 & 0.007 & 3.585 \\
\hline IPINC & -0.227 & 0.233 & 0.629 & 0.797 \\
\hline IPOUTC & -0.355 & 0.484 & 0.487 & 0.701 \\
\hline Constant & -3.211 & 19.499 & 0.000 & 0.040 \\
\hline$R^{2}$ & 0.426 & & & \\
\hline
\end{tabular}

${ }^{*},{ }^{* *},{ }^{* *}$ Significant at $0.1,0.05$ and 0.01 , respectively.

a Logistic regression results are fairly easy to interpret; logistic regression results allow one to estimate directly the probability of an event occurring. The parameters of a model are estimated using the maximum-likelihood method; that is, the coefficients that make the observed results most likely are selected. In general, the left-hand side of a logistic regression is "logit" or "log odds ratio". In the case of a model that predicts whether or not a firm patents the model is:

Logit $($ patent $)=$ Constant $+B_{1}{ }^{*}$ RDSPEND $+B_{2}{ }^{*}$ INHASTECH $+B_{3}{ }^{*}$ BIORCRT ...

The " $B$ " associated with each independent variable is the portion of the log odds ratio that is attributable to that variable. In the logistic model, which predicts whether or not a firm patents, the $B$ associated with "BIORCRT", for example, is 0.434 . The "Wald" associated with each independent variable refers to the Wald statistic, which is in this case similar to a chi-square statistic, and provides an estimate of the significance of the variable. In the case of "BIORCRT" the Wald statistic is 21.465 , which will occur less then one thousand of a percent of the time by chance alone, hence it is significant (see Sig.).

The final value presented for each independent variable is the exponential of $B$ (the log odds ratio), or the simple odds ratio associated with a one-unit change in the independent variable in terms of the dependent variable. If $B$ is positive, its exponent will be greater than 1 , which means the odds will increase. If $B$ is negative, the exponent will be less than one, which means that the odds will decrease. In the case of "BIORCRT", for example, a firm 
they used a higher number of different recruiting methods to fill biotech positions. The intensity of patenting was also positively associated with inhouse R\&D capability.

In contrast to the first model, firms that patent more intensively have a higher proportion of their products and processes at an earlier (R\&D) stage of development. Furthermore, the innovation intensity model supports previous research on the importance of VC: patenting firms are more successful in accessing capital from angel investors, family, friends, VC funds and collaborative alliances, that is, private, relational capital market linkages. ${ }^{8}$ Innovative firms are also less likely to rely on government sources of information. The evidence on IP flows is somewhat ambiguous. On the one hand, as in the first model, innovative firms are more likely to transfer IP rights to foreign firms than are less innovative firms. On the other hand, they are also less likely to acquire IP rights from foreign firms. This suggests that technologically progressive (i.e. patent-intensive) firms are less dependent on foreign codified knowledge inputs (at least those acquired through formal IP agreements), being able to satisfy their knowledge requirements from local or internal sources.

To get a deeper understanding of the relative significance of local and global networks, we produced a number of cross-tabulations of the survey data. First, we explored the relationship between innovation (patenting) and the presence of foreign biotech employees (see Table 6). Interestingly, we found that innovative firms are almost six times more likely to hire foreign employees than are non-innovative ones. We also examined the relationship between patenting and flows of knowledge (intellectual property). The findings show that patenting firms are about two and a half times more likely to grant IP rights to foreign firms compared to nonpatenting ones. They are also almost twice as likely as non-innovative companies to acquire IP rights from foreign firms. Taken together, these findings appear to highlight the importance of strong external-indeed global-knowledge flows (both embodied and disembodied) in the innovative success of Canadian biotech firms.

that uses two recruiting methods is $1.543^{2}$ or 2.381 times more likely to innovate than a firm that uses only one recruiting method; a firm that utilizes three methods is $1.543^{3}$ or 3.674 times as likely to innovate as a firm that uses only one method. In the case of a dummy variable, such as the numerical value assigned to the yes/no answer of "IPOUTF" an $\exp (B)$ value of 3.585 simply means that a firm that grants a right to foreign firms is about three and a half times more likely to innovate than a firm that does not grant such rights (this explanation is derived from Daniere and Takahashi (1999) and Norusis and SPSS Inc. (1990)).

\footnotetext{
${ }^{8}$ Unfortunately, the survey design does not permit us to determine the location of these private/relational sources.
} 
Table 5. Linear regression analysis—number of existing/pending patents

\begin{tabular}{|c|c|c|}
\hline Variable & $B$ & Sig. \\
\hline RDSPEND & $8.501^{-6}$ & 0.164 \\
\hline INHSTECH & $0.486^{\star}$ & 0.103 \\
\hline BIORCRT & $0.232^{\star \star \star}$ & 0.002 \\
\hline KNOWFLWGG & -0.110 & 0.778 \\
\hline OBSTHR & -0.180 & 0.495 \\
\hline INTERNAL & $-6.6^{-2}$ & 0.858 \\
\hline CODIFIED & -0.202 & 0.247 \\
\hline TACIT & 0.184 & 0.160 \\
\hline GOVERNMENT & $-0.441^{\star \star \star}$ & 0.005 \\
\hline NUMBER OF COLLABORATIVE AGREEMENTS & $-0.457^{-2}$ & 0.351 \\
\hline SPINOFF? & 0.363 & 0.208 \\
\hline SIZE & $-2.127^{-4}$ & 0.207 \\
\hline CAPITAL RAISED PER EMPLOYEE & $2.793^{-6}$ & 0.777 \\
\hline CAPITAL MARKET LINKAGES & $7.669^{-3 \star \star}$ & 0.020 \\
\hline OBSTACLE CAPITAL & 0.144 & 0.659 \\
\hline STAGE-RD & $1.257^{\star \star *}$ & 0.000 \\
\hline STAGE-PRECLINICAL & 0.582 & 0.284 \\
\hline STAGE-REGULATORY & 0.947 & 0.342 \\
\hline IPINF & $-0.808^{\star \star}$ & 0.047 \\
\hline IPOUTF & $1.043^{\star \star \star}$ & 0.011 \\
\hline IPINC & 0.105 & 0.796 \\
\hline IPOUTC & 0.712 & 0.117 \\
\hline Constant & -0.829 & 0.155 \\
\hline$R^{2}$ & 0.209 & \\
\hline
\end{tabular}

${ }^{*},{ }^{* *},{ }^{* *}$ Significant at $0.1,0.05$ and 0.01 , respectively.

To further understand the nature of these global partnerships and collaborative arrangements, we explored the geography of these agreements more explicitly. Recall that the findings reported in Table 4 indicated a positive relationship between patenting and the number of collaborative agreements in which the firm is engaged. Table 7 shows that the

Table 6. Biotech innovation and global knowledge flows

\begin{tabular}{|c|c|c|c|c|c|c|}
\hline \multirow{2}{*}{$\begin{array}{l}\text { Does the firm } \\
\text { innovate? }\end{array}$} & \multicolumn{2}{|c|}{$\begin{array}{c}\text { Foreign } \\
\text { employees? }(\%)^{\mathrm{a}}\end{array}$} & \multicolumn{2}{|c|}{$\begin{array}{l}\text { IP acquired from } \\
\text { foreign firms }(\%)^{\mathrm{a}}\end{array}$} & \multicolumn{2}{|c|}{$\begin{array}{l}\text { IP granted to foreign } \\
\text { firms }(\%)^{\mathrm{a}}\end{array}$} \\
\hline & Yes & No & Yes & No & Yes & No \\
\hline Yes & 29.0 & 71.0 & 23.0 & 77.0 & 21.9 & 78.1 \\
\hline No & 5.3 & 94.7 & 12.1 & 87.9 & 8.3 & 91.7 \\
\hline
\end{tabular}

${ }^{\mathrm{a} C h i-s q u a r e ~ s i g n i f i c a n t ~ a t ~} 0.01$. 
geography of this collaboration exhibits a strong distance-decay effect. In short, geography matters for collaboration: Canadian biotech firms are more likely to engage in collaborative agreements with Canadian partners. ${ }^{9}$

Having said this, analysis of the relationship between patenting and collaboration by country suggests a stronger relationship between collaboration and patenting when the partners involved are American or European (Table 8). Amongst all firms, 42.5 percent report an existing or pending patent. If, on the other hand, the firm has a collaborative agreement with an American or European partner, the innovation rate increases to between 60 and 61 percent. While a similar relationship is evident when the firm collaborates with a Canadian partner, this effect appears to be somewhat weaker. For those firms with a Canadian collaborator, the proportion that patents is just under 51 percent. In other words, although collaboration with Canadian partners is more prevalent than international collaboration, the impact of this collaboration on the likelihood of patenting is not as great as the impact of international (US or European) collaboration.

Table 7. The geography of collaboration

\begin{tabular}{lr} 
Country & No. of collaborative \\
\hline Canada & 326 \\
USA & 159 \\
Europe & 99 \\
Rest of world & 52
\end{tabular}

Table 8. Innovation and collaboration geography

\begin{tabular}{|c|c|c|c|c|c|c|c|}
\hline \multirow{2}{*}{$\begin{array}{l}\text { Does the } \\
\text { firm } \\
\text { innovate? }\end{array}$} & \multicolumn{2}{|c|}{$\begin{array}{c}\text { Canadian } \\
\text { collaborators }(\%)^{\mathrm{a}}\end{array}$} & \multicolumn{2}{|c|}{$\begin{array}{c}\text { American } \\
\text { collaborators }(\%)^{\mathrm{a}}\end{array}$} & \multicolumn{2}{|c|}{$\begin{array}{c}\text { European } \\
\text { collaborators }(\%)^{a}\end{array}$} & \multirow[b]{2}{*}{ All } \\
\hline & Yes & No & Yes & No & Yes & No & \\
\hline Yes & 50.8 & 32.5 & 60.2 & 34.2 & 60.8 & 37.3 & 42.5 \\
\hline No & 49.2 & 67.5 & 39.8 & 65.8 & 39.2 & 62.7 & 57.5 \\
\hline
\end{tabular}

${ }^{\mathrm{a} C h i-s q u a r e ~ s i g n i f i c a n t}$ at 0.01 .

\footnotetext{
${ }^{9}$ It should be acknowledged that, although we are defining "distance" in traditional physical terms here, it is highly likely that cultural or institutional distance is equally relevant to this discussion, as Gertler (2004) has demonstrated.
} 


\section{Conclusions: A Complex Geography of Global and Local Linkages}

The results presented in this paper illuminate the two sides of the innovation process in biotechnology: the local and the non-local/global. They also underscore the importance of internal resources and competences in permitting the firm to make the best use of opportunities for learning-by-interacting. Our analysis of the 1999 Canadian Biotech Use and Development Survey highlights the importance of in-house technological capability (and absorptive capacity) for the success of innovation in biotechnology, as was demonstrated by the importance of in-house $R \& D$ and the intensity of efforts to recruit biotech workers. These results are in line with findings from previous work that emphasizes the importance of a firm's internal resources and capabilities (Penrose, 1959; Kay, 1993; Cohendet et al., 1999).

However, our analysis also provides some new and more detailed insights into the geography of knowledge flows supporting innovation in biotech firms. The findings suggest that to be successful innovators, Canadian biotech firms must be externally oriented. Patenting biotech firms make more extensive use of codified sources of knowledge, and are more likely to recruit staff from outside Canada than are non-patenting firms. This implies a substantial reliance on non-local sources of knowledge and on international knowledge flows (embodied and otherwise). In addition, while innovative firms make more extensive use of collaborative arrangements than non-innovative firms, and while the majority of collaborative partners are to be found in Canada, the presence of a foreign partner in such a relationship appears to be more strongly associated with patenting than is the presence of a Canadian partner. Finally, patenting firms are more likely than non-patenting firms to grant IP rights from their research to foreign firms, suggesting the importance of global relationships for the commercialization of knowledge once produced.

Although we highlight the importance of global networks in our findings, our analysis also reveals the value of local networks. The clearest suggestion of this comes in our finding that "local"/relational linkages are especially important for raising capital (and, presumably, the expertise that comes with it). While it is highly likely that angel investors, family and friends are truly local, when it comes to $\mathrm{VC}$ and financing from collaborative alliances, the relevant partners may not necessarily be local (although the literature suggests that there is still a strong probability that they will be close by).

The striking evidence on the external orientation of innovative biotech firms in Canada dispels some of the ambiguity evident from previous work. Whereas researchers have noted the importance of local sources of VC and knowledge (Niosi, 2000b; Cooke, 2002a), others argue that knowledge flows are becoming more dispersed (Cortright and Mayer, 2002). We show that in Canada both knowledge flows and capital flows (in the form of payments received from licensing IP) are increasingly extending beyond 
the immediate locality and nation to foreign partners and sources. This external orientation may be a product of both the location and the age of the industry. Possibly, as suggested by the Ernst and Young (2002) review of biotech in Canada, the limitations to the entrepreneurial experience and local financial resources available to Canadian biotech firms relative to their counterparts in the USA, the UK or other European countries, compel these firms to search elsewhere for the capital and expertise that would enhance their chances of commercial success. Second, the above results may also reflect the changing nature of innovation in a maturing biotech industry. It is likely that as firms expand, grow and develop they will need to extend their search to resources and markets located farther away.

Thinking more broadly about the implications of our analysis for a theory of biotech clusters, it seems clear that innovative biotechnology firms must be both open to new knowledge (embodied and otherwise) from a wide range of sources and reliant on local relationships for capital and know-how. This suggests that those places that are best suited to fostering innovation in biotechnology will not simply be places that provide local "buzz", but must also be well connected to globally circulating knowledge and people. If so, then how should we understand the role of place in supporting biotech innovation? In other words, why is it that biotech firms cluster in relatively few places, and why is this geography becoming more concentrated over time, not less?

We suggest that innovative biotech firms cluster geographically for two basic reasons. First, as the Novartis case suggests, they choose those locations that maximize opportunities to benefit from local relationships with other firms, ${ }^{10}$ investors, and institutions of research and higher learning (producers of knowledge in embodied and disembodied forms) ${ }^{11}$ Second, they select those places that best enable them to attract and retain their most critical resource-highly educated workers-from elsewhere but also, we can infer, from local sources. Recent research on this subject suggests that local quality of place-broadly defined to include not only the usual list of physical, recreational and cultural amenities, but also social characteristics such as low "barriers to entry" and the presence of a critical mass of creative people-is vital to ensure that local communities are open to inflows of knowledge and talent (Florida, 2002; Gertler et al., 2002).

Nevertheless, despite the importance of "the local", it is clear from the analysis in this paper that strong linkages to foreign markets, collaborators, labour pools and other sources of knowledge remain crucial for enabling innovation in biotechnology firms.

\section{Acknowledgements}

The authors are grateful to Fred Gault and Antoine Rose of the Science, Innovation and Electronic Information Division, Statistics Canada, for their invaluable support and advice. 


\section{References}

Allen, J. (2000) Power/economic knowledge: symbolic and spatial formations, in: J. R. Bryson et al. (Eds) Knowledge, Space, Economy, pp. 15-33 (London: Routledge).

Amin, A. (2000) Organisational learning through communities of practice, paper presented at the workshop on The Firm in Economic Geography, University of Portsmouth.

Asheim, B. T. and Gertler, M. S. (2005) The geography of innovation: regional innovation systems, in: J. Fagerberg et al. (Eds) The Oxford Handbook of Innovation, pp. 291-317 (Oxford: Oxford University Press).

Bathelt, H. et al. (2004) Clusters and knowledge: local buzz, global pipelines and the process of knowledge creation, Progress in Human Geography, 28, pp. 31-56.

Cohen, W. and Levinthal, D. (1990) Absorptive capacity: a new perspective on learning and innovation, Administrative Science Quarterly, 35, pp. 128-152.

Cohendet, P. et al. (1999) Knowledge coordination, competence creation and integrated networks in globalised firms, Cambridge Journal of Economics, 23, pp. 225-241.

Cooke, P. (2001a) New economy innovation systems: biotechnology in Europe and the USA, Industry and Innovation, 8(3), pp. 267-289.

Cooke, P. (2002a) Biotechnology clusters as regional, sectoral innovation systems, International Regional Science Review, 25(1), pp. 8-37.

Cortright, J. and Mayer, H. (2002) Signs of Life: The Growth of Biotechnology Centers in the U.S (Washington: The Brookings Institution Center on Urban and Metropolitan Policy).

Daniere, A. G. and Takahashi, L. M. (1999) Environmental behavior in Bangkok, Thailand: a portrait of attitudes, values, and behaviour, Economic Development and Cultural Change, 47(3), pp. $525-557$.

Delaney, E. J. (1993) Technology search and firm bounds in biotechnology: new firms as agents of change, Growth and Change, 24(Spring), pp. 206-228.

Dyer, G. (2002a) Biotechnology: the sector's hidden giant, Financial Times, 31 October.

Dyer, G. (2002b) Seeking freedom in New England, Financial Times, 8 May, pp. 13.

Ernst and Young (2002) Beyond Borders: The Canadian Biotechnology Report, (Toronto).

Feldman, M. P. (2000) Location and innovation: the new economic geography of innovation, spillovers and agglomeration, in: G. L. Clark et al. (Eds) The Oxford Handbook of Economic Geography (Oxford: Oxford University Press).

Feldman, M. P. (2001) Where science comes to life: university bioscience, commercial spin-offs, and regional economic development, Journal of Comparative Policy Analysis: Research and Practice, 2, pp. 345-361.

Florida, R. (2002) The Rise of the Creative Class (New York: Basic Books).

Gertler, M. S. (2004) Manufacturing Culture: The Institutional Geography of Industrial Practice (Oxford: Oxford University Press).

Gertler, M. S. et al. (2002) Competing on Creativity: Placing Ontario's Cities in North American Context (Toronto: Ministry of Enterprise, Opportunity and Innovation, and the Institute for Competitiveness and Prosperity), Available at www.utoronto.ca/progris/web_files/recentpub.htm.

Kay, J. (1993) Foundations of Corporate Success (Oxford: Oxford University Press).

Klevorick, A. K. et al. (1995) On the sources and significance of interindustry differences in technological opportunities, Research Policy, 24, pp. 185-205.

Levin, R. C. et al. (2001) Appropriating the returns from industrial research and development, Brookings Papers on Economic Activity, pp. 783-820.

Lundvall, B. -Å. and Johnson, B. (1994) The learning economy, Journal of Industry Studies, 1, pp. 23-42.

Malmberg, A. and Maskell, P. (2002) The elusive concept of localization economies: towards a knowledge-based theory of spatial clustering, Environment and Planning A, 34, pp. 429-449. 
Maskell, P. and Malmberg, A. (1999) Localised learning and industrial competitiveness, Cambridge Journal of Economics, 23, pp. 167-185.

McNiven, C. (2001a) Biotechnology Use and Development-1999, Cat. No.88F0006XIE01007 (Ottawa: Statistics Canada).

McNiven, C. (2001b) Practices and Activities of Canadian Biotechnology Firms: Results from the Biotechnology Use and Development Survey-1999, Cat. No.88F0006XIE01011 (Ottawa: Statistics Canada).

Niosi, J. (2000a) Explaining Rapid Growth in Canadian Biotechnology Firms (Ottawa: The Science and Technology Redesign Project, Statistics Canada).

Niosi, J. (2000b) Strategy and performance factors behind rapid growth in Canadian biotechnology firms, in: J. de la Mothe and J. Niosi (Eds) The Economic and Social Dynamics of Biotechnology, Vol. 21 (Boston, Dordrecht and London: Kluwer Academic).

Niosi, J. and Bas, T. G. (2001) The competencies of regions: Canada's clusters in biotechnology, Small Business Economics, 17, pp. 31-42.

Niosi, J. and Dalpé, R. (2003) Industrial networks in Canadian biotech, Paper presented at the Fifth Annual Meeting of the Innovation Systems Research Network, Ottawa, May.

Norusis, M. J., SPSS Inc. (1990) SPSS Advanced Statistics User's Guide (Chicago, IL: SPSS).

Penrose, E. (1959) The Theory of the Growth of the Firm (Oxford: Basil Blackwell).

Powell, W. W. et al. (2002) The spatial clustering of science and capital: accounting for biotech firmventure capital relationships, Regional Studies, 36(3), pp. 291-305.

Prevezer, M. (2001) Ingredients in the early development of the U.S. biotechnology industry, Small Business Economics, 17(1), pp. 17-29.

Storper, M. and Veuables, A. J. (2004) Buzz: face-to-face contact and the urban economy, Journal of Economic Geography, 4(4), pp. 351-370.

Teece, D. J. (1986) Profiting from technological innovation: implications for integration, collaboration, licensing and public policy, Research Policy, 15, pp. 285-305.

Zucker, L. G. and Darby, M. R. (1996) Star scientists and institutional transformation: patterns of invention and innovation in the formation of the biotechnology industry, Proceedings of the National Academy of Science, 93(Nov), pp. 12709-12716.

Zucker, L. G., Darby, M. R. and Armstrong, J. (1998a) Geographically localized knowledge: spillovers or markets?, Economic Inquiry, 36, pp. 65-86.

Zucker, L. G. et al. (1998b) Intellectual human capital and the birth of the U.S. biotechnology enterprises, American Economic Review, 88(1), pp. 290-306. 